\title{
The Power of Events: An Introduction to Complex Event Processing in Distributed Enterprise Systems
}

\author{
David Luckham \\ Department of Electrical Engineering, Stanford University, USA \\ luckhamestanford.edu
}

\begin{abstract}
Complex Event Processing (CEP) is a defined set of tools and techniques for analyzing and controlling the complex series of interrelated events that drive modern distributed information systems. This emerging technology helps IS and IT professionals understand what is happening within the system, quickly identify and solve problems, and more effectively utilize events for enhanced operation, performance, and security. CEP can be applied to a broad spectrum of information system challenges, including business process automation, schedule and control processes, network monitoring and performance prediction, and intrusion detection.

This talk is about the rise of CEP as we know it today, its historical roots and its current position in commercial markets. Some possible long-term future roles of CEP in the Information Society are discussed along with the need to develop rule-based event hierarchies on a commercial basis to make those applications possible. The talk gives empahsis to the point that "Rules are everywhere" and that mathematical formalisms cannot express all the forms that are in use in various event processing systems.
\end{abstract}

